\title{
Effect of Brief Focused Attention Meditation on Theory of Mind
}

\author{
Piyush $^{1}$, Pankaj Srivastava ${ }^{2}$, Harvinder Pal Singh ${ }^{3}$, Arun Garg ${ }^{4}$
}

\section{ABSTRACT}

Background: The ability to infer and understand the mental states of others termed as Theory of Mind, is an intrinsic part of social interaction. Most efforts have been made to study disorders related to ToM i.e. depletion in ToM and considerably less is known about variables that may enhance ToM. Further, effects of meditation have been studied extensively in domains of Attention and Emotional regulation, yet only few studies have studied effect of meditation on ToM. In current study, brief intervention methodology was used to access effects of meditative practice on Theory of Mind. Two groups were formed, first group consisted of subject who were treated with a particular type of meditation termed as Focused Attention meditation and second group was treated with a pseudo meditation. Treatment used was of 20-minute duration in both groups and subjects of both groups were without any prior long term experience in any form of meditation. Result: After that subject self-reported mindfulness, attention and awareness via MAAS- state scale and then participated in a ToM experiment called YONI task, to access any changes in their ability to do ToM, for both cognitive ToM and affective ToM. The results indicated that brief Focused Attention meditation enhanced both Cognitive ToM and Affective ToM.

Keywords: Mediation, Focused attention, Theory of Mind, Cross-sectional, Brief-intervention.

Meditation can be understood as a form of mental training that aims to improve subjects core psychological capabilities like attention, emotional regulation etc. But Mindfulness practices and meditation are not synonymous, either in theory or in practice. However most of the mindfulness based interventions utilize some form of meditative practices. The word mindfulness may be used to describe a psychological trait, a practice of cultivating mindfulness, a mode or state of awareness, or a psychological process. One of the most commonly cited definitions of mindfulness is the awareness that arises through "paying attention in a particular way: on

\footnotetext{
${ }^{1}$ Research Scholar, Department of Philosophy, Panjab University, Chandigarh, India

${ }^{2}$ Assistant Professor, Department of Philosophy, Panjab University, Chandigarh, India

${ }^{3}$ Lecturer, Managerial Economics, Lovely Professional University |Research Scholar, IBS Business School Hyderabad, India

${ }^{4}$ Resource Person, Department of Philosophy, Post Graduate Government College, Sector 46, Chandigarh, India *Responding Author

Received: February 15, 2017; Revision Received: March 16, 2017; Accepted: March 23, 2017

(C) 2017 Piyush, Srivastava P, Singh H, Garg A; licensee IJIP. This is an Open Access Research distributed under the terms of the Creative Commons Attribution License (www.creativecommons.org/licenses/by/2.0), which permits unrestricted use, distribution, and reproduction in any Medium, provided the original work is properly cited.
} 


\section{Effect of Brief Focused Attention Meditation on Theory of Mind}

purpose, in the present moment, and nonjudgmentally" (Kabat-Zinn, 1994, p. 4). Descriptions of mindfulness provided by most other researchers are somewhat similar. Baer, for example, defines mindfulness as "the non-judgmental observation of the ongoing stream of internal and external stimuli as they arise". However, two roots can be traced back to conceptualization of mindfulness in scientific studies, firstly by Jon Kabat-Zinn who derived the concept from Buddhist philosophy while trying to strip it from the religious and philosophical assumptions, and equating the word mindfulness to Buddhist pali term "sati" which drives from a root, meaning 'to remember,' but as a mental factor signifying presence of mind, attentiveness to the present, rather than the faculty of memory regarding the past and is defined as "paying attention with purpose, non-judgementally and while in the present movement (Kabat-Zinn ,1994,2005) .The second root can be traced back to Ellen langer, which originated independently of any reference to eastern contemplative traditions, her concept originated from a social psychological approach while researching about mindlessness and thus generating a contrastive definition. Mindfulness here is defined as an active state of mind characterized by novel distinctionsdrawing that results in being situated in the present, sensitive to context, having different perspective and guided but not governed by rules and routines. Whereas mindlessness is defined as an inactive state of mind characterized by reliance on distinctions or categories drawn in past, where past determines the present, being trapped in a single perceptive, insensitive to context and governed by rules and routines. Both views are similar, in as both emphasize focus on momentto-moment awareness, but differ in their conceptualization, Jon Kabat view focuses on cultivation of mindfulness and gaining new insights, while langer views conceptualizes mindfulness as a universal human capacity, that need not be enhanced through practice rather is maintained by maintaining an orientation on present and alternateness to distinctions, context and multiple perspectives. In the present study Kabat-Zinn view is taken to conceptualize mindfulness as a practice, that can be enhanced and needs to be cultivated.

Further, in cognitive science, to understand meditation as a process, the better way to classify meditation is in term of cognitive, affective and behavioural mechanism, the process it is exploiting. A single meditation process might employ multiple mechanism e.g. a single meditation might use multiple cognitive mechanism or use mixture of cognitive, affective and behavioural mechanism, which can be further classified in terms of primary mechanism and secondary mechanisms. Classification on basis of cognitive processes involved in meditative practices was recently proposed as: Attentional Family, Constructive family, Deconstructive family. Those groups of practices which are referred to as "attentional family" are those that train variety of processes related to regulation of attention i.e. capacity to manipulate the orientation and aperture of attention, to monitor, detect, and disengage from distractors, and to reorient attention toward a chosen object, while strengthening the capacity to be aware of the processes of thinking, feeling, perceiving and uses awareness directly, which is understood as a cognitive function of being aware of the processes of distraction from the chosen object and not to be experientially fused (or cognitively fused or object mode), with the objects of consciousness or 


\section{Effect of Brief Focused Attention Meditation on Theory of Mind}

experience. A further classification has been done on basis of attention style used during meditation, namely focused attention (FA) and open monitoring (OM) (chan and polich 2006; Lutz et al. 2008a).Focused attention style refers to attention style in which attention is focused on a single object in a sustained manner and also includes regulatory skills of monitoring the focus of attention, detecting distraction, disengaging attention from the source of distraction and refocusing on the object (Lutz et al. 2008a). FA involves selective attention on a chosen object e.g. localized sensation caused by respiration and to sustain the focus monitoring of quality of attention is essential during the process, attention may wander away from the singular chosen object and subject will be required to detect this wandering and thus restore it to the singular object again e.g. a common practice is to keep or maintain sustained attention on localised sensation of breath i.e. when its inhaled and exhaled (Vedic literature described it as parana and aparana,and Buddhist literature as Anapanasati),but attention may wander off to some other sensation in the body or to thoughts, then to bring back attention to singular object, in this case sensation of breath, first mediator must be able to detect this wandering and not get lost in other non-relevant sensations or thoughts(experiential fusion), then after it has been noticed that attention has wandered to other objects, disengagement of attention is required from the nonrelevant sensation or thought and lastly redirection or reengagement of attention to chosen singular object. So, focused attention involves three things namely focused or concentrated attention, awareness (which helps to detect attention wandering) and thirdly attention regulatory skills of disengagement and reengagement. In this form of meditation, progress can be measured in terms of three things i.e. degree of effortlessness of maintaining the attention to chosen object, how less frequently process of disengagement and reengagement are happening and thirdly how continuous is the process of awareness. This is important point to be noted as the primary goal of these focused based attention is not to gain control over attentional focus but by using attentional focus to maintain awareness continuously. Second sub-classification in the attentional family is called open monitoring $(\mathrm{OM})$ meditation, this group includes those practices that have three main features namely, no explicit focus on object, non-reactive meta-cognition monitoring and nonreactive awareness of automatic cognitive and emotional interpretation of sensory, perceptual and endogenous stimuli.OM practices initially use FA training to calm the mind and reduce distraction and then meditator gradually reduces the focus on any explicit object.OM is also referred to as mindfulness meditation (Cahn and Polich,2006).Another difference between the two is that unlike FA meditation, OM meditation doesn't entail attentional biases resulting in selection and de-selection process. Secondly, constructive family type of practices are those which strengthens the psychological pattern that harness well-being. It's been proposed that well-being is been effected by targeting maladaptive self-schema and replacing them with more adaptive conceptualization of self, where self-schema is understood as latent beliefs and conceptions about self and are thought to underline and inform thought and emotions and also impact patterns of brain function. Two cognitive mechanisms have been proposed in this family that are cognitive reappraisal and perspective taking. Cognitive reappraisal is the process of changing how subject thinks about situations and events (thoughts, emotions) in such a way that 


\section{Effect of Brief Focused Attention Meditation on Theory of Mind}

his response to them is modified and has been associated with brain areas that are related to cognitive control, which includes brain areas like the dorsomedial, dorsolateral, and ventrolateral prefrontal cortex and posterior parietal cortex. The second process that have been associated with constructive meditations is that of perspective taking which means the act of considering how oneself or another would feel in a particular situation Perspective taking is involved with experience of social emotions, it is found to be diminished in psychopaths and also to be a helpful in reducing intergroup prejudice. Imaging studies have pointed that there is no single neural mechanism related to perspective taking, but different brain networks. It's been proposed that, both cognitive reappraisal and perspective taking are used to target maladaptive or neuro adaptive patterns, example thatcan be given, is of transformation of empathy into compassion i.e. "Hearing a crying baby on an airplane, for example, might first elicit a feeling of distress followed by aversion. This experience can be transformed by taking the perspective of the baby's mother, thereby triggering a sense of warmth and compassion, and also by reinterpreting the sound of the baby's cries, viewing the experience as an opportunity to cultivate kindness and concern rather than an impediment to one's own well-being. By systematically cultivating compassion in this manner, responding to aversive stimuli with altruistic concern may eventually become automatic. Thus, such changes may be studied within the framework of habit formation, which is associated with various facets of physical and psychological well-being". These type of practices have received little attention in scientific study, some of the studied practices in this class are compassion based meditation. Thirdly, group of meditative practices referred to as deconstructive family aims to undo maladaptive cognitive patterns by exploring the dynamics of perception, emotion, cognition and this exploration might result into insights about ones internal models of self, other and world. It has been proposed by the authors that central mechanism in deconstructive family is of 'self-inquiry', where self-inquiry is been defined as a process of investigation the dynamics and nature of conscious experience. This family has received very less attention in term of scientific study.

\section{Theory of Mind (ToM)}

In 19th century German aesthetics employed the word Einfuhlüng (meaning "feeling into") to describe the sensation one feels when viewing an inspiring piece of art.Then in 20th century Theodor Lipps, ( some consider him as first proponents of simulation theory) proposed that this same process (Einfuhlüng) may have something to do in coming to understand the minds of others i.e. he not only argued for Einfuhlüng as a concept that is central for the philosophical and psychological analysis of our aesthetic experiences but also has to be understood as being the primary basis for recognizing each other as minded creatures. Thus Einfuhlüng was transformed from a concept of philosophical aesthetics into a central category of the philosophy of the social and human sciences and in 1909 psychologist Edward Titchener translated Lipp's conception of Einfuhlüng to "empathy". In "On the Optical Sense of Form: A contribution to Aesthetics" (1873), Robert Vischer used the term "Einfühlung" in a more technical sense-and in using the substantive form he indicates that it is a worthy object of philosophical analysis. Lipps pointed 


\section{Effect of Brief Focused Attention Meditation on Theory of Mind}

about a "universal appreciative empathy" and a general "empathy of nature." and also used empathy in order to explain certain perceptual illusions. From his perceptive empathy "refers to any mental activity on part of the observer that is triggered in the perceptual encounter with an external stimulus and that has to be understood as being constitutive for our comprehension of an object qua object. From empiricist view, sense data is the fundamental basis for our investigation of the world and from phenomenological perspective, our perceptual encounter with aesthetic objects and our appreciation of them as being beautiful —our admiration of a beautiful sunset, for example-seems to be as direct as our perception of an object as being red or square. By appealing to the psychological mechanisms of empathy, philosophers intended to provide an explanatory account of the phenomenological immediacy of our aesthetic appreciation of objects. In beginning of the $20^{\text {th }}$ century philosophers like Prandtl (1910), Stein (1917), Scheler (1973) argued considerably about empathy and Lipp's core concept of empathy was understood as the primary epistemic means for our perception of other person's mind. His argument for empathy was closely tied to a thorough critique of what was widely seen at that time as the only alternative for conceiving of knowledge of other minds, that is, Mill's inference from analogy.

Contemporary authors/philosophers/psychologists have offered a variety of definitions to the term "empathy". Feshbach proposed that the process of empathy involved three components:1) the ability to discriminate and identify the emotional state of another 2) the capacity to take the perspective of the other 3) the evocation of a shared affective response, these three factors are accepted by most authors, yet some few more components have been also proposed. Some have argued for role of sustained self-other distinction during shared affective response and mimicked motor movements that result from observing another move as a type of "motor empathy. In the cognitive science, authors have divided these factors into two groups: cognitive empathy and affective empathy. Ability to share the emotional state of another person is termed "affective empathy" and the capacity for understanding another person's experience and perspective is termed "cognitive empathy" (Davis, 1983).

The ability to infer the thoughts and feelings of others is critical for appropriate and effective social interactions and discourse comprehension, but it is not sufficient. Belief understanding does not guarantee emotion understanding; emotion understanding does not guarantee empathy; and empathy does not guarantee sympathy/compassion as manifested by kindness to people (Davis \& Stone, 2003). Hence, empathy is the link between knowing the thoughts and feelings of others (ToM), experiencing them (Emotional Empathy), and responding to others in caring, supportive ways (compassion). Broadly speaking, empathy refers to the reactions of one individual to the observed experiences of another (Davis, 1994). Some scholars view empathy as a cognitive process, stressing the ability to engage in the cognitive process of adopting another individual's psychological perspective. This process, which can be termed cognitive empathy (and when including an inference on affective aspects can also be known as affective ToM or affective cognitive ToM), may be defined as an active attempt by one person to get "inside" 


\section{Effect of Brief Focused Attention Meditation on Theory of Mind}

another's mind or to approach someone mentally through a deliberate intellectual effort. In other words, cognitive empathy describes a situation in which the subject is an active agent deliberately attempting to step outside the self and "into" the other's experiences; it involves a cognitive recognition of the emotions of others. This process may involve perspective taking (Eslinger, 1998) and ToM (Shamay-Tsoory, Tomer, Goldsher, Berger, \& Aharon-Peretz, 2004). It is thought to be dependent on several cognitive capacities, such as cognitive flexibility and memory (Davis, 1994; Eslinger, 1998); Grattan, Bloomer, Ar- chambault, \& Eslinger, 1994). Other studies in the field have used a definition of empathy that showcases its affective aspects. Such studies refer to the ability to experience affective reactions to the observed experiences of others as "affective empathy" (Davis, 1994). Here, empathy is understood as an emotional reaction of the observer when perceiving that another is experiencing or is about to experience an emotion. Thus there is difference between cognitive empathy (affective cognitive ToM) and emotional or affective empathy. Whereas cognitive empathy involves cognitive understanding of another person's perspective, emotional empathy includes appropriating these feelings, at least on a gross level (pleasant-unpleasant); ( Mehrabian \& Epstein, 1972). It has also been suggested that affective empathy is the basis for cognitive empathic ability. For cognitive ToM many brain regions have been identified as participating in cognitive ToM including medial prefrontal cortex (mPFC), superior temporal sulcus (STS), temporoparietal junction (TPJ), and temporal poles (Frith \& Singer, 2008; Saxe \& Powell, 2006; Saxe, Whitfield-Gabrieli, \& Scholz, Pelphrey, 2009; Schilbach et al., 2012; Van Overwalle \& Baetens, 2009; Young, Camprodon, Hauser, Pascual-Leone, \& Saxe, 2010). It has been further suggested that the TPJ is mainly in charge of transient mental inferences about other people .Studies (Young et al. 2010) have shown that a disruption in the functioning of the right TPJ using TMS can result in a reduction of the participant's use of mental state information in moral judgments and mPFC, on the other hand, supports the attribution of more enduring traits and qualities of others, as well as of the self (Saxe \& Powell, 2006; Schilbach et al., 2012; Van Overwalle \& Baetens, 2009). Another distinction has been made on basis of Interpersonal and intrapersonal ToM and empathy, where former refers to empathy and ToM towards other (Self to other), later refers to empathy and ToM towards self (Self to Self).Also its to be noted that Mirror neurons are thus active both during the execution and observation of an action and it has been suggested that, given the observationexecution properties of the mirror neuron system, it is particularly well suited for providing the pertinent mechanism for motor empathy, imitation, and emotional contagion.

Further there are three main theories in cognitive science that tend to provide explanation for theory of mind namely: The Theory-Theory, Simulation-Theory and The theory of mind mechanism (ToMM). Conceptual change or theory-theory has been accepted as one possible explanation for TOM (Wellman et al., 2001). Theory-theorists believe that children learn a set of causal laws, or theories, about the beliefs and desires of people in general (Gopnik, 1993). Children then use these causal laws to explain behaviour observed in others, to predict desires

and behaviours, and to perform other related ToM tasks. Secondly, Simulation theory also has 


\section{Effect of Brief Focused Attention Meditation on Theory of Mind}

been accepted as possible explanation for ToM (Gallese \& Goldman, 1998). It posits that when a person ("A") tries to understand another ("B"), A simulates what he would do in B's place, and attributes the result to B. More specifically i.e. humans perform ToM by representing the mental states of others, and then using their own decision-making systems to operate on these foreign mental states to predict others' behaviour; similar processes can be used to explain observed behaviour, making backward inferences (Laura M. Hiatt). Gallese and Goldman (1998) describe the distinction between this and theory-theory as, while theory-theory is performed as a “'detached' theoretical activity," simulation theory involves attempting to mimic or impersonate the mental state of another. Lastly, theory of mind mechanism (ToMM) also offers a possible explanation, it allows people to generate and represent multiple possible beliefs. It has been proposed that this mechanism is fully functional in even very young children. The second mechanism provides a selection process (SP) that uses inhibition to reason about others' beliefs, such as inhibiting a true-belief to select a false-belief answer; "ToMM-SP", authors break it down into four steps:

(1) identify candidate belief possibilities

(2) provide a priori weights to the candidates, with true-belief receiving the highest weight

(3) adjust the weights given the belief inquiry

(4) select the highest-weighted candidate as the answer.

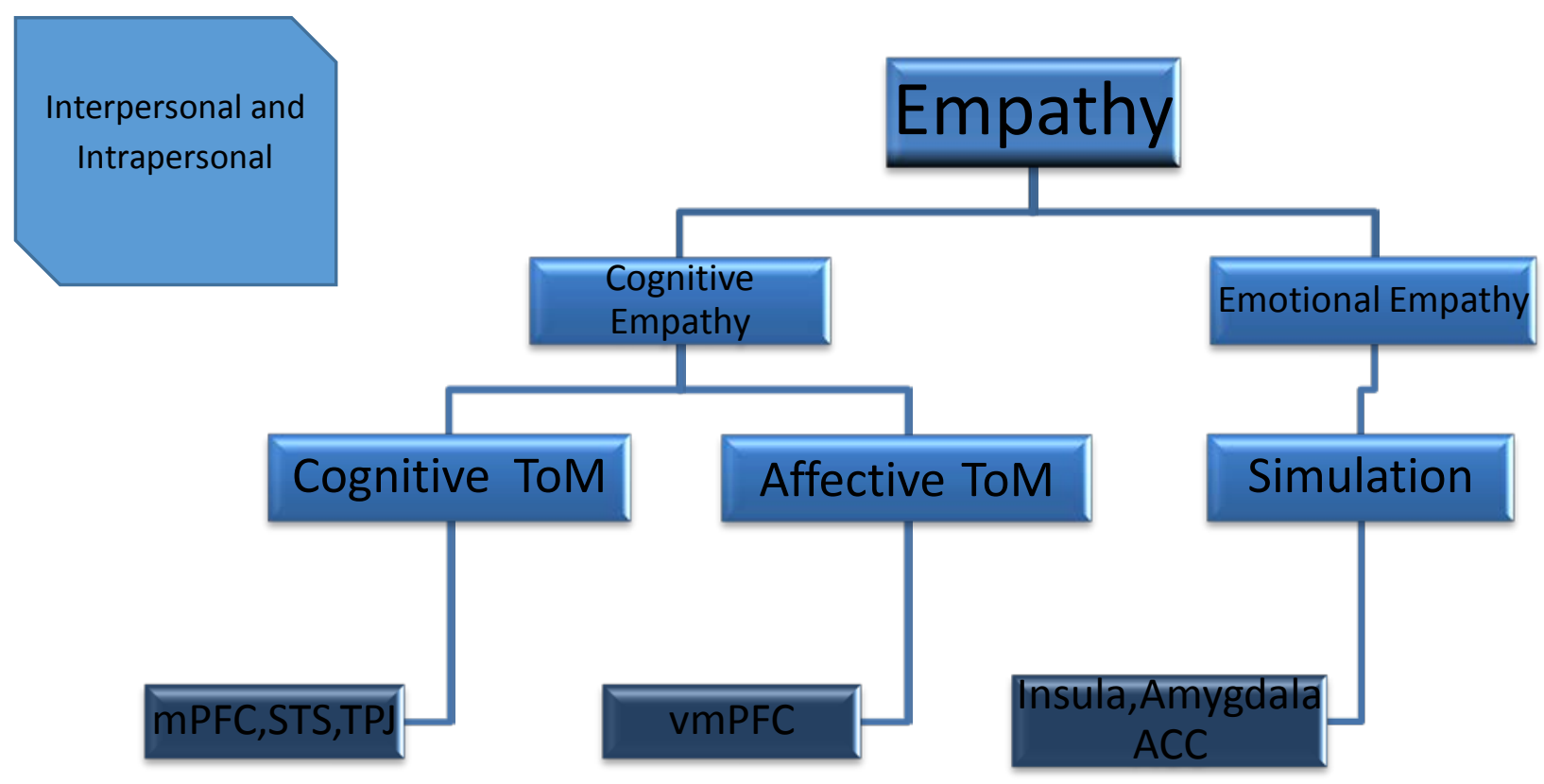

[Figure - 0] 


\section{Effect of Brief Focused Attention Meditation on Theory of Mind}

\section{Meditation and Theory of Mind (ToM) Interaction}

In recent years, mindfulness interventions have been shown to remediate a range of clinical problems and also influence certain aspects of social cognition like meta-cognition. One of the most important aspect of social cognition is Theory of Mind. Some, preliminary investigations have revealed that ToM can be improved by certain factors like nasal admiration of oxytocin, compassion based training and reading literary fictions. Further, research in other domains have predicted a linkage between mindfulness and ToM e.g. it has been shown that mindfulness enhances executive attention, where research in executive attention has shown that when the faculty is used effectively by subjects, it enables them to form multifaceted evaluations of other social agents, that are not rigid to a stereotype based evaluations. Also, from neuroscience perceptive it's been shown that cortical regions that support ToM and self-referential mental activity (e.g., medial prefrontal cortex, temporal parietal junction) also play an important functional role during mindfulness meditation. So, these possible linkages have motivated researchers to study the relationship between ToM and mindfulness and indeed some preliminary research have found some significant results, e.g. study done to see the effect of mindfulness training (MAT) (intervention based) on empathy, has showed diminished response towards emotional empathy, another study has found strong correlates between mindfulness score (CAMS-R) and perspective taking i.e. cognitive empathy/ ToM and increase in perspective taking / cognitive ToM (PT, IRI) after a mindfulness training program (intervention based) has been found. Also a cross-selection study has found that there in increase in cognitive empathy /cognitive empathy ToM (RMET) and emotional empathy (Cyberball) after a brief mindfulness intervention. But it also to be noted that a study using long-term intervention produced no effect on cognitive empathy / cognitive empathy ToM (RMET). Also, it might be noted that a previous study conducted by [P Parimoo, S Sharma, N Chopra] showed positive increase in terms of effect of brief open-monitoring mindfulness meditation on both cognitive and affective theory of mind (ToM). So, to address this gap and to find out whether this effect can also be seen in focused attention meditation, we conducted a brief intervention study with focused attention meditation, with a different experimental paradigm termed as YONI task.

\section{METHODOLOGY}

\section{Overview}

Research in meditation is still in its infancy and there are three type of methodologies that are been employed to understand meditation i.e. Cross-sectional, Brief intervention studies and Longitudinal intervention studies. Cross-sectional, studies two groups at a particular time, one is control i.e. people who have never meditated in their life and other is meditators group (expert). The idea behind this kind of methodology is simple, that to easily see the effects of meditation on subjects who had years of training, just compare them with normal population who did not had

such training, while controlling various dimensions like age, socio-economic status etc. This comparison can be in neurological or psychophysical terms. Many studies have shown effects in terms brain structure and function, but there is a major flaw in these type of studies i.e. they can 


\section{Effect of Brief Focused Attention Meditation on Theory of Mind}

never inform researcher about direction of causality which caused such effects To put it simply it is not easy to control these groups on various control factors, so it difficult to reasonable rule out other variable which might have produced the effect and these studies are co-relational in nature i.e. they study the co-variation between two variables, so it difficult to apply causal attribution to meditation itself and rule out other factors which might be present in the personality of subjects in terms of interest in meditation, temperament, intensity, motivation etc. Secondly, Brief intervention studies or compare data from a two or more groups at a time just after the brief intervention. One group gets meditation training (in minutes) and other control. Initially researchers used no intervention for controls and simply compared it with meditation group, but that was problematic as both groups conditions were not controlled matched, so now for brief intervention studies control group is also provided with a treatment, like relaxation technique of same amount of time as meditators group spend on brief meditation. Advantage of such methodology is that they are easy to conduct and give results about the state effect only. Lastly, Longitudinal intervention studies This methodology studies or compare data from a two or more groups at several time points. They can range from few days to years, although current studies have used it from few days to 3-5 months. These studies are conducted in naïve subjects, in which subjects are randomly assigned to two are more treatment groups, one of which will consist of actual meditation practice and other will consist of pseudo meditation or treatment based on certain cognitive strategies which are known not to be included in the actual meditation group. Thus are able to extract specific meditation effects. They are difficult to conduct and also special attention has to be paid to control for variables that may be confounded with meditation practice such as diet, lifestyle.

\section{Methodology Used}

Brief intervention study will be conducted with a relaxation technique termed as group 1, which will serve as a pseudo meditation i.e. control and focused attention meditation will be used as a treatment in group 2.

\section{Material Used}

Since two groups are formed for treatment, treatment will be served via audio scripts via headphones. Group 1 audio script will consist of relaxation instruction and Group 2 script will consist of focused attention meditation. Both scripts are time matched to 20 minutes and have a bell sound at the end, to convey end of treatment.

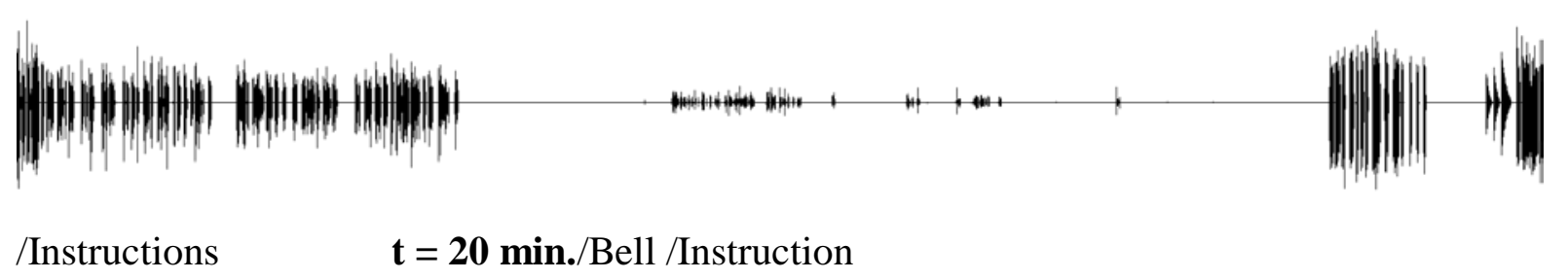




\section{Effect of Brief Focused Attention Meditation on Theory of Mind}

\section{Tools Used}

Three tools were deployed, firstly Mindful Attention Awareness Scale (MAAS-State, [35]), a questionnaire (5-item) via mouse, that probes levels of mindful-attention and awareness via a 7point rating scale $(0=$ not at all; $6=$ very much). Secondly, various Socio-Demographic information e.g. age, English reading comprehension level (1 to 5), Social Economic Classification levels by Social Economic Classification of India and Psychological/Neurological Disorder (Yes or No). Thirdly, for measuring both aspects of ToM (Affective and Cognitive), we used Yoni task, a paradigm introduced by Shamay-Tsoory and colleagues. The "Yoni" task has been used in studies of neurological and psychiatric populations, as well as in a neuroimaging study. In Yoni task subject is introduced to a cartoon face of the main character named "Yoni", which is always located in the centre of the screen. In the stimulus "Yoni" is presented at the centre with four other coloured pictures in each of the screen quadrants in combination with one object of a semantic category (e.g., flowers, toys, fruits). The task is divided into three major conditions namely: affective ToM (aff), cognitive ToM (cog), and a control condition (phy) and two minor conditions namely first order ToM (e.g. "Yoni is thinking of__") and second order ToM (e.g. "Yoni is thinking of the fruit that _ wants"). Further a statement is displayed on the upper margin of the screen which have to be completed by the subjects e.g.: "Yoni likes the fruit that ... likes." (affective ToM condition); "Yoni is thinking of the flower that ... is thinking of." (cognitive ToM condition); and "Yoni has the toy that ... has." (physical condition). All three conditions were kept almost identical with difference in the shape of the mouth of Yoni (Happy, Sad, Neutral), eye gaze of Yoni (directed Yoni gaze and non-directed Yoni gaze) and the sentence. Facial expressions and eye gaze direction of the four faces in the corners were systematically balanced, that is, in half of the items Yoni's eye gaze was straight, in the other half Yoni's eye gaze was towards the direction of the correct choice, and in half of the items two of the small faces had the same facial expression as Yoni in order to avoid simple face matching. Subjects were required to employ ToM for both the affective and the cognitive condition, but only analysis of physical attributes for control/ physical items was needed. Subjects responded(via computer mouse as fast as they can) by choosing one of the four available options( every item had only one correct answer) in which they were required to merge the three cues namely, facial expression(shape of mouth),the eye gaze and verbal cues (what was said in the sentence).The stimulus was given in three phases namely Phase A, Phase B and Phase C. Phase A executed first order trials of condition "cognitive", "affective", and "physical" in a mixed design (8 trials each),Phase B executed a mixture of first order "cognitive" and "affective" (4 trials each) trials and second order affective trials (24) in a mixed design and at last Phase C executed second order trials of condition "cognitive" (24 trials), "affective" (12 trials), and "physical" (6 trials) in a mixed design. 


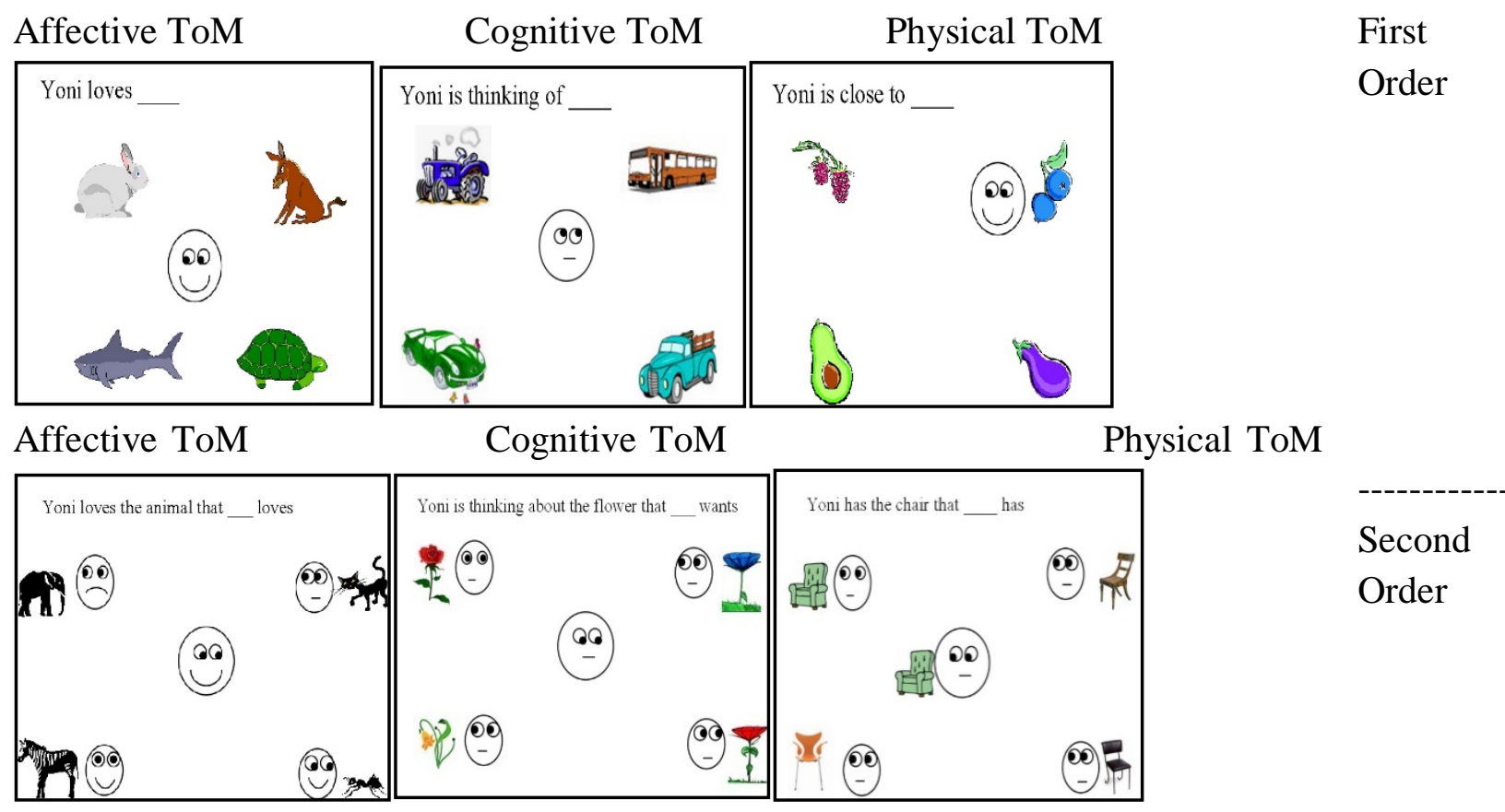

\section{[Figure: 1]}

\section{Sample}

An a priori sample size calculation performed on $\mathrm{G}^{*}$ Power $3.0 .10(\alpha=.05, \mathrm{~d}=0.6$, power $=$ $80 \%$ ) revealed a requirement of 72 participants. So, the sample of study consisted of 72 subjects (36 for Group 1 and 36 for Group 2). Sample of the study was selected by random sampling via word of mouth. The age range was from 20-32-year-old.

\section{Procedure}

Participants were greeted and were told that the research accessed people's reaction to different stimulus i.e., participants were blind to the purpose of the inquiry. After that eye test was performed and then subjects were instructed about various ethical considerations about the study. After taking appropriate consent, they were randomly assigned to one of the treatment condition i.e. Focused Attention and control. The experimental manipulation was then introduced. All participants were instructed to close their eyes, relax and listen to scripted audio instructions (via headphones) and that a bell would chime after 20 minutes to signal the end of this activity. In meditation group instructions were of focused attention meditation and in control group, relaxation instructions were used (pseudo meditation). Following 20 minutes' treatment subjects filled the Mindful Attention Awareness Scale (MAAS-State). On completion of the MAAS-S, ToM YONI task started. After the task, subjects filled various Socio-Demographic information e.g. age, English reading comprehension level (1 to 5), Social Economic Classification levels by Social Economic Classification of India and Psychological/Neurological Disorder (Yes or No). 


\section{RESULTS}

\section{Controls}

Total number of subjects were 72 (36 for each group), all male population, with age range of 2032 and mean age of group 1 (meditation) was 25.00, and of group 2 (control) was 24.638.No, significant difference was found in term of age with $t$ test $(t=0.4258)$ of $p$ value $=0$. 6716. Further mean values of English reading comprehension were 3.055 for group 1 and 2.805 for group 2, with no significant effect with $\mathrm{t}$ test $(\mathrm{t}=0.7984)$ of $\mathrm{p}$ value $=0.4279$. Further SEC mean values were 3.722 for group 1 and 3.583 for group 2, with no significant effect with test $(t=0.4324)$ of p value $=0.6667$. Also, no subject reported Psychological or Neurological Disorder .

\begin{tabular}{|l|l|l|l|}
\hline Age & Mean & t value & P value \\
\hline Group & 25.000 & 0.4258 & $0.6716 \mathrm{~N}^{*}$ \\
\hline Meditation & 24.638 & & \\
\hline Control & & \\
\hline [Table - 1] & \multicolumn{2}{l|}{} \\
\hline English Reading Comprehension & t value & P value \\
\hline Group & Mean & 0.7984 & $0.4279 \quad \mathrm{~N}^{*}$ \\
\hline Meditation & 3.055 & & \\
\hline Control & 2.805 & & \\
\hline
\end{tabular}

[Table - 2]

Social Economic Classification of India

\begin{tabular}{|l|l|l|l|}
\hline Group & Mean & t value & P value \\
\hline Meditation & 3.722 & 0.4324 & $0.6667 \mathrm{~N}^{*}$ \\
\cline { 1 - 2 } Control & 3.583 & & \\
\hline
\end{tabular}

[Table - 3]

\section{Manipulation}

The success of the experimental manipulation was confirmed, such that subjects in the mindfulness condition reported a greater awareness of the present moment (i.e. state mindfulness) than their counterparts in the control condition, $\mathrm{t}=4.203, \mathrm{p}<.001$, with mean value of 4.212 (0.4372) for group 1 and mean value of 3.765 (0.4644) for group 2. Thus, as expected, subjects who underwent the mindfulness treatment reported higher levels of state mindfulness. Mindreading performance, conceptualized as affective ToM and cognitive ToM and measured by the YONI task, was better for participants in the mindfulness than control condition, in both conditions, with $\mathrm{t}$ value $=2.186$ of $\mathrm{p}$ value $=.0321$ and with accuracy score of $(80.613 \%$ $75.405 \%$ ) for affective ToM condition and t value $=4.850$ of $\mathrm{p}$ value $<0.001$ and with accuracy score of (87.96 \% - 79.62\%) for cognitive ToM, confirming our prediction. 
Effect of Brief Focused Attention Meditation on Theory of Mind

\begin{tabular}{|l|l|l|l|}
\hline Mindful Attention Awareness Scale & t value & P value \\
\hline Group & Mean & 4.203 & $<.001$ Sig* \\
\hline Meditation & $4.212(0.4372)$ & & \\
\hline Control & $3.765(0.4644)$ & \\
\hline [Table -4] & \multicolumn{2}{l|}{} \\
\hline YONI task- Affective ToM & Accuracy Score & t value & P value \\
\hline Group & 2.186 & $=.0321 \quad$ Sig* \\
\hline Meditation & 80.613 & \\
\hline Control & 75.405 & $\mathrm{t}$ value & \\
\hline [Table -5] & 4.850 & P value \\
\hline YONI task - Cognitive ToM & & $<.001 \quad$ Sig* \\
\hline Group & Accuracy Score & \\
\hline Meditation & 87.96 & 79.62 &
\end{tabular}

\section{[Table - 6]}

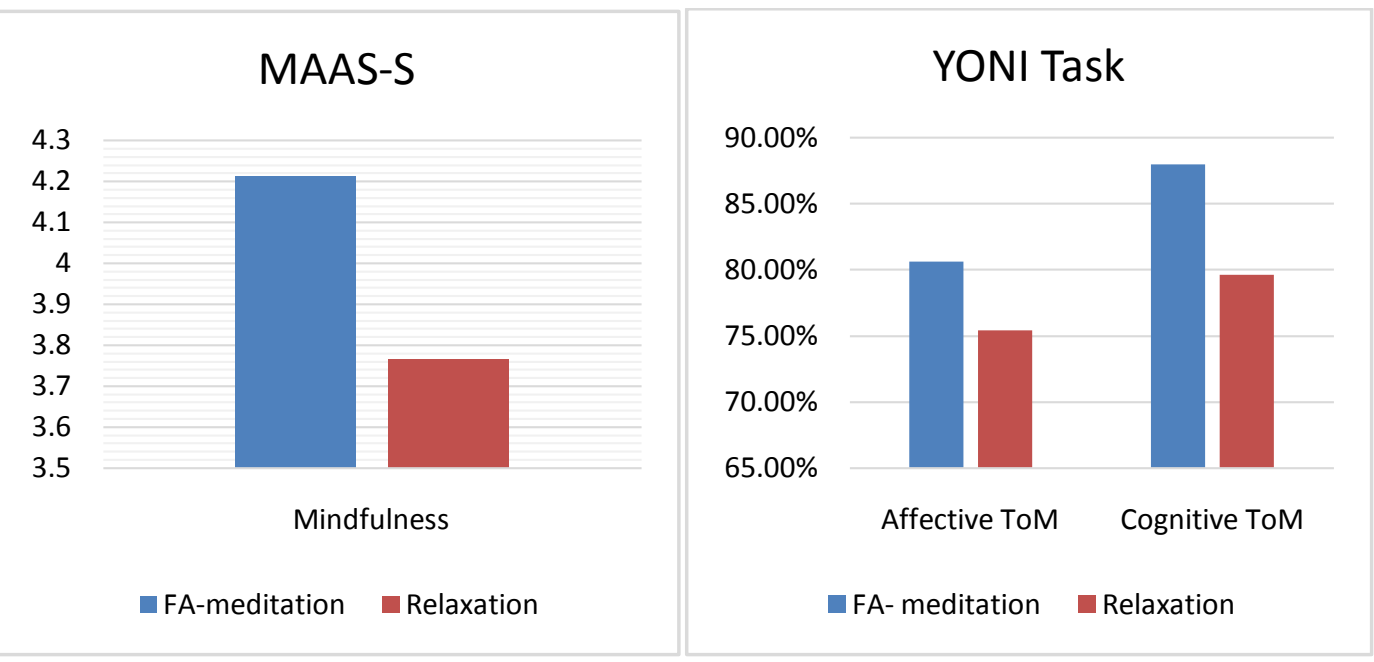

[Graph - 1]

[Graph - 2]

\section{Conclusions and Implication}

The finding that Focused attention meditation has clear influence on ToM, has implications for both clinical and normal settings. In clinical settings, impact of this type of meditation on socialcognitive disorders might prove helpful and in normal settings it might help individuals to perceive each other mental states more effectively, resulting in more social well-being. This study also provides motivation for another study to look for the long term effect of FA meditation on ToM and also to see comparative difference between FA and OM meditation.

\section{Acknowledgments}

The author appreciates all those who participated in the study and helped to facilitate the research process. 


\section{Effect of Brief Focused Attention Meditation on Theory of Mind}

\section{Conflict of Interests}

The author declared no conflict of interests.

\section{REFERENCES}

Baer, R. A. (2003). Mindfulness training as a clinical intervention: A conceptual and empirical review. Clinical Psychology: Science and Practice, 10, 125-143.

Barnett MA, ed. Empathy and related responses in children. New York: Cambridge University Press; 1987.

Baron-Cohen S, Wheelwright S. The empathy quotient: an investigation of adults with Asperger syndrome or high functioning autism, and normal sex differences. J Autism Dev Disord Apr 2004;34(2):163-175.

Blair RJ, ed. Empathic dysfunction in psychopathic individuals. New York: Cambridge University Press; 2007.

Brown KW, Ryan KM (2003) The benefits of being present: Mindfulness and its role in psychological well-being. Journal of Personality and Social Psychology 84: 822-848.

Creswell JD, Way BM, Eisenberger NI, Lieberman MD (2007) Neural correlates of dispositional mindfulness during affect labeling. Psychosomatic Medicine 69: 560-565.

Dahl, C. J., Lutz, A., \& Davidson, R. J. (2015). Reconstructing and deconstructing the self: Cognitive mechanisms in meditation practice. Trends in Cognitive Sciences, 19(9), 515523. http://doi.org/10.1016/j.tics.2015.07.00125. Mason, M.F. et al. (2007) Wandering minds: the default network and stimulus-independent thought. Science 315, 393-395

Davis, D. M., \& Hayes, J. a. (2011). What are the benefits of mindfulness? A practice review of psychotherapy-related research. Psychotherapy (Chicago, Ill.), 48(2), 198-208. http://doi.org/10.1037/a0022062

Decety J, Jackson PL. The functional architecture of human empathy. Behavioural and cognitive neuroscience reviews June 2004 2004;3(2):71-100.

Decety, J. et al. (2013) An fMRI study of affective perspective taking in individuals with psychopathy: imagining another in pain does not evoke empathy. Front. Hum. Neurosci. 7, 89

Desbordes, G., Negi, L. T., Pace, T. W. W., Wallace, B. A., Raison, C. L., \& Schwartz, E. L. (2012). Effects of mindful-attention and compassion meditation training on amygdala response to emotional stimuli in an ordinary, non-meditative state. Frontiers in Human Neuroscience, 6(November), 1-15. http://doi.org/10.3389/fnhum.2012.00292

Dvash, J., \& Shamay-Tsoory, S. G. (2014). Theory of Mind and Empathy as Multidimensional Constructs. Topics in Language Disorders, 34(4), 282-295. http://doi.org/10.1097/TLD.000000000000004

Farb NAS, Segal ZV, Mayberg H, Bean J, McKeon D, et al (2007). Attending to the present: Mindfulness meditation reveals distinct neural modes of self reference. Social Cognitive and Affective Neuroscience 2: 313-322.

Fox, K.C.R. et al. (2015) The wandering brain: meta-analysis of functional neuroimaging studies of mind-wandering and related spontaneous thought processes. Neuroimage 111, 611-621 


\section{Effect of Brief Focused Attention Meditation on Theory of Mind}

Frith CD, Frith U (2012) Mechanisms of social cognition. Annual Review of Psychology 63: 287-313.

Gross, J.J. (2001) Emotion regulation in adulthood: timing is everything. Curr. Dir. Psychol. Sci. 10, 214-219 61.

Guastella AJ, Einfeld SL, Gray KM, Rinehart N, Tonge BJ, et al (2010) Intranasal oxytocin improves emotion recognition for youth with autism spectrum disorders. Biological Psychiatry 67: 692-694.

Ho“ lzel BK, Lazar SW, Gard T, Schuman-Olivier Z, Vago DR, et al (2011). How does mindfulness meditation work? Proposing mechanisms of action from a conceptual and neural perspective. Perspectives on Psychological Science 6: 537-559.

Ho“lzel BK, Carmody J, Vangel M, Congleton C, Yerramsetti SM, et al (2011) Mindfulness practice leads to increases in regional brain gray matter density. Psychiatry Research: Neuroimaging 191: 36-43.

Hofmann, S. G., Grossman, P., \& Hinton, D. E. (2011). Loving-kindness and compassion meditation: Potential for psychological interventions. Clinical Psychology Review, 31(7), 1126-1132. http://doi.org/10.1016/j.cpr.2011.07.003

Holzel, B. K., Lazar, S. W., Gard, T., Schuman-Olivier, Z., Vago, D. R., \& Ott, U. (2011). How Does Mindfulness Meditation Work? Proposing Mechanisms of Action From a Conceptual and Neural Perspective. Perspectives on Psychological Science, 6, 537-559. http://doi.org/10.1177/1745691611419671

Kabat-Zinn, J. (1994). Wherever you go there you are: Mindfulness meditation in everyday life. New York, NY: Hyperion

Keng, S. L., Smoski, M. J., \& Robins, C. J. (2011). Effects of mindfulness on psychological health: A review of empirical studies. Clinical Psychology Review, 31(6), 1041-1056. http://doi.org/10.1016/j.cpr.2011.04.006

Kidd DC, Castano E (2013) Reading literary fiction improves theory of mind. Science 342: 377380.

Klimecki, O.M. et al. (2014) Differential pattern of functional brain plasticity after compassion and empathy training. Soc. Cogn. Affect. Neurosci. 9, 873-879.

Lamm, C. et al. (2007) The neural substrate of human empathy: effects of perspective-taking and cognitive appraisal. J. Cogn. Neurosci. 19, 42-58.

Lawrence EJ, Shaw P, Baker D, Patel MX, David AS. Separating Cognitive from Affective Empathy: Data from Two Clinical Groups. The Quarterly Journal of Experimental Psychology: Section A 2005;58:1534-1559

Mascaro JS, Rilling JK, Negi LT, Raison CL (2013) Compassion meditation enhances empathic accuracy and related neural activity. Social Cognitive and Affective Neuroscience 8: 4855.

Mascaro, J.S. et al. (2013) Compassion meditation enhances empathic accuracy and related neural activity. Soc. Cogn. Affect. Neurosci. 8, 48-55. 


\section{Effect of Brief Focused Attention Meditation on Theory of Mind}

Mascaro, J.S. et al. (2013) Compassion meditation enhances empathic accuracy and related neural activity. Soc. Cogn. Affect. Neurosci. 8, 48-55

P Parimoo, S Sharma, N Chopra (2016), Effect of Brief Open Monitoring Mindfulness Mediation on Theory of Mind, International Journal of Indian Psychology, Volume 3, Issue 4, No. 63, ISSN 2348-5396 (e), ISSN: 2349-3429 (p), DIP: 18.01.100/20160304, ISBN: 978-1-365-32518-2

Pettigrew, T.F. and Tropp, L.R. (2008) How does intergroup contact reduce prejudice? Metaanalytic tests of three mediators. Eur. J. Soc. Psychol. 38, 922-934.

Plumb, J. C., \& Rhatigan, D. L. (2007). The case for mindfulness-based approaches in the cultivation of empathy: Does nonjudgm ... Page 1 of 1 The case for mindfulness-based approaches in the cultivation of empathy: Journal of Marital and Family Therapy, 33(4), 2011-2011. http://doi.org/10.1111/j.1752-0606.2007.00034.x

Rodgers CR, ed. A theory of therapy, personality and interpersonal.

Ruby, P. and Decety, J. (2004) How would you feel versus how do you think she would feel? A neuroimaging study of perspective-taking with social emotions. J. Cogn. Neurosci. 16, 988-999

Semple, R. J. (2010). Does Mindfulness Meditation Enhance Attention? A Randomized Controlled Trial. Mindfulness, 1(2), 121-130. http://doi.org/10.1007/s12671-010-0017-2

Stueber K. Empathy. The Stanford Encyclopedia of Philosophy (Fall 2008 Online Edition) Edward N Zalta (ed); 2008.

Stueber, Karsten, "Empathy", The Stanford Encyclopedia of Philosophy (Winter 2014 Edition), Edward N. Zalta (ed.).

Tang YY, Ma Y, Feng H, Wang J, Feng S, et al (2009) Central and autonomic nervous system interaction is altered by short-term meditation. Proceedings of the National Academy of Sciences of the United States of America 106: 8865-8870.

The Wiley Blackwell Handbook of Mindfulness Amanda Ie (Editor), Christelle T. Ngnoumen (Editor), Ellen J. Langer (Editor) ISBN: 978-1-118-29487-1,1240 pages,February 2014, Wiley-Blackwell.

Webb, T.L. et al. (2012) Dealing with feeling: a meta-analysis of the effectiveness of strategies derived from the process model of emotion regulation. Psychol. Bull. 138, 775-808.

How to cite this article: Piyush, Srivastava P, Singh H, Garg A (2017), Effect of Brief Focused Attention Meditation on Theory of Mind, International Journal of Indian Psychology, Volume 4, Issue 2, No. 94, ISSN:2348-5396 (e), ISSN:2349-3429 (p), DIP:18.01.142/20170402, ISBN:9781-365-84229-0 